Proc. Estonian Acad. Sci. Geol., 2004, 53, 1, 13-27

\title{
Fractality in geology: a possible use of fractals in the studies of partial melting processes
}

\author{
Alvar Soesoo $^{\text {a }}$, Jaan Kalda ${ }^{\mathrm{b}}$, Paul Bons ${ }^{\mathrm{c}}$, Kristjan Urtson ${ }^{\mathrm{d}}$, \\ and Volli Kalm ${ }^{\mathrm{d}}$ \\ ${ }^{\text {a }}$ Institute of Geology at Tallinn Technical University, Estonia pst. 7, 10143 Tallinn, Estonia; \\ Alvar.Soesoo@gi.ee \\ b Institute of Cybernetics at Tallinn Technical University, Akadeemia tee 21, 12618 Tallinn, \\ Estonia \\ c Institut für Geowissenschaften, Eberhard Karls Universität Tübingen, D-72076 Tübingen, Germany \\ ${ }^{d}$ Institute of Geology, University of Tartu, Vanemuise 46, 51014 Tartu, Estonia
}

Received 29 April 2003, in revised form 9 June 2003

\begin{abstract}
The use of nonlinear and chaotic dynamics and fractal approaches in the studies of the Earth has increased in the last decade. A large number of geological objects show a power-law or fractal distribution, which suggests that these objects do not require any characteristic length-scale or time in their definition. Fractals can be used in studies of magma mixing and mingling, mantle convection, lava flows, percolation properties of veins and ore mineralization, and to separate geochemical anomalies. It is shown that the width of migmatitic leucosomes in the Estonian basement rock follows power-law distributions and shows fractal properties. Despite the differences in size and number of measured leucosomes and veins, differences in host rock types and formation conditions, the studied leucosome and vein data set shows good power-law distributions with exponents, $m$, usually between 1.0 and 1.9. The spacing of leucosomes and veins in rock section is not a random feature, but fractal (fractal dimension $D=0.77-0.79$ ). Using the power-law size distribution for the melt batches, the total volume of the melt phase, as well as the relative contributions of the largest batch (dominant for $m<1$ ) and of the smallest batches (dominant for $m>1$ ), are estimated. The relationship between the magmatic leucosome width-distribution exponent, and the melt batch size-distribution is derived.
\end{abstract}

Key words: fractality, power-law distribution, self-similarity, migmatite, Estonian basement.

\section{INTRODUCTION}

The last years have witnessed the increasing activities in the use of nonlinear and chaotic dynamics, fractals, and approach of complex systems in different Earth and social sciences. Geology is not an exception. This development points to the emergence of a new paradigm. 
Soon after Mandelbrot (1967) introduced the concept of fractals, it came into use in different sciences including Earth sciences. The mathematical theory of fractals is described in Mandelbrot (1982).

The question "How long is a coastline, for instance the Norwegian fiord coast?", has no exact answer. The length measure depends on the resolution of the ruler that is used. One can use boxes of a certain size to measure the coastline. Obviously, the smaller the box, the more boxes are needed to cover the coast. Decreasing the size of the box will result in a more "exact" length of the coastline. However, there are physical limits in re-sizing the measuring box. One way of representing these measuring results is to plot the number of boxes against the size of the measuring box on a log-log plot, for a large range of box sizes. The results fall on a trend with a negative slope, which gives the "fractal dimension" of the coast. Had the coast been a straight line, the number of boxes would be inversely proportional to box size and the fractal dimension would be 1 . For the Norwegian coastline the fractal dimension is 1.52 (Feder 1988), the dimension which lies between a straight line (with dimension 1) and a surface (with dimension 2).

Fractal geometry is well suited to the description of geological objects that exhibit scaling behaviour. The most important feature of fractal geometry is the lack of any homogenization scale. The main argument for potential fractal scaling in geology is the absence of characteristic length-scales in a number of geological observations. For example, in the hydrocarbon industry, such scaling laws provide a key to predicting the nature of fracturing (also below the limit of seismic resolution), which can significantly influence reservoir parameters. In the groundwater, contaminant transport is particularly sensitive to the properties and scaling of fracture systems. In earthquake hazard assessment, the main issue is the validity of the Gutenberg-Richter law for predicting the probability of the occurrence of large earthquakes.

By now a number of fractal studies in geomorphology, petrology, oil and gas geology, ore geology, sedimentology, geophysics, geochemistry, and other geological disciplines have been published and this approach has proven to be successful in geological research. The aim of this paper is to give an overview of the use of fractals in geology and show an example of how it can be applied to studies of partial melting and melt accumulation within the crust.

\section{AN EXAMPLE OF A FRACTAL}

Let us construct a fractal and find its dimension. Consider the Sierpinski Triangle - a simple example of a fractal (Peitgen et al. 1992). We start with a triangle (Fig. 1A). Next, let us draw the lines connecting the midpoints of the sides and cut out the centre triangle. We have reached the stage of the triangle which consists of three new triangles, with each side half the length of a side of the original triangle (Fig. 1B). Each "new" triangle looks exactly like the original triangle when magnified by a factor of 2 (magnification or scaling factor). Now 
Fig. 1. The Sierpinski Triangle - a simple example of a fractal. We start with a triangle (A) and draw the lines connecting the midpoints of the sides. Each "new" triangle looks exactly like the original triangle when magnified by a factor of 2 (B-E). Repeating the division many times, we see that smaller triangles are exactly the same as the triangle one step before when magnified by a factor of two.

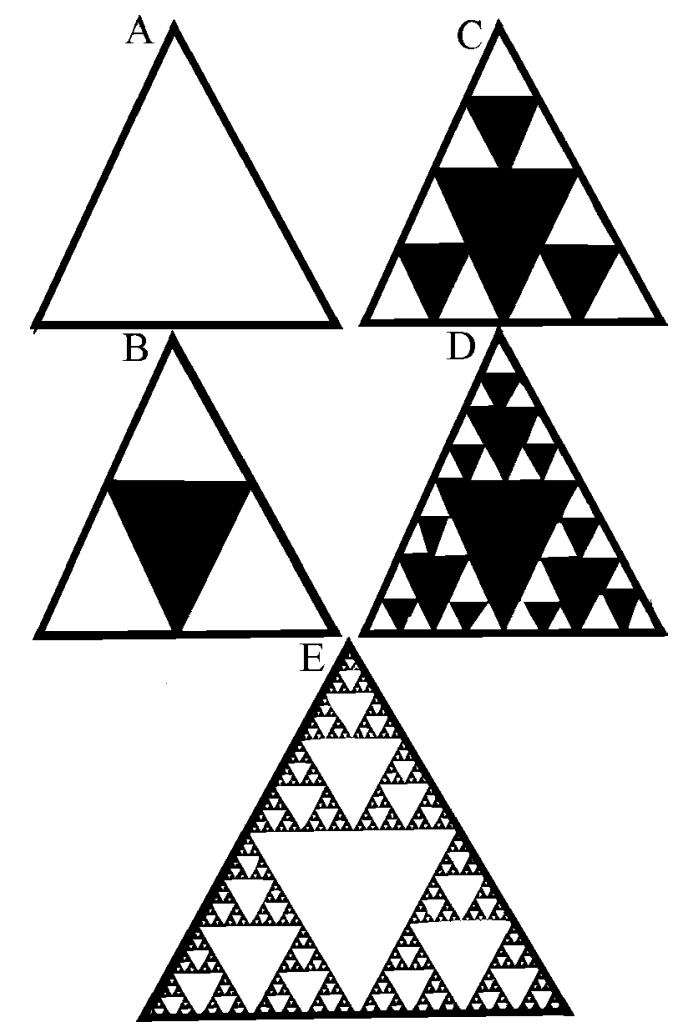

we simply repeat the dividing as many times as we wish. It is easy to see that each smaller triangle is exactly the same as the triangle one step before when magnified by a factor of two. Thus, the Sierpinski Triangle is self-similar.

Now we can compute the fractal dimension $(D)$ of the Sierpinski Triangle. Notice that the second triangle is composed of three miniature triangles exactly like the original. The length of any side of one of the miniature triangles could be multiplied by 2 to produce the entire triangle $(S=2)$. The resulting figures consist of three separate identical miniature pieces $(N=3)$. We find $D$ by considering $3=2^{D}$, giving $\log 2^{D}=\log 3$, and finally $D=\log 3 / \log 2$, which in the present case is 1.58 . The dimension of the Sierpinski Triangle is 1.58 , and is not an integer: it is fractal.

This method of finding fractal dimensions can be used only for strictly selfsimilar fractals. Other ways of computing fractal dimensions include, for example, mass or box counting. The fractal dimension indicates the degree of detail or crinkliness in a shape. So, in the Euclidean space dimensions, the Sierpinski Triangle lies between the line (dimension 1) and surface (dimension 2).

In theory, a fractal dimension is a non-integer topological dimension of the space that embeds an object with a complex geometry. A common brief definition of a fractal set is one with no characteristic length-scale. However, Mandelbrot (1982) stressed that such a definition cannot directly apply to natural fractal sets, 
which have their natural upper and lower limits. Thus, for fractals in nature, the above definition applies only within a limited scale range. Nevertheless, fractal dimension has turned out to be a powerful tool to measure complex forms which were previously immeasurable, such as mountains, the Earth's surface, clouds, rock texture, deformed crustal sections, trees, etc. Some very convoluted surfaces, such as a tree's foliage or the internal surfaces of lungs, but also rock texture or surface, may effectively approach three-dimensional structures. We can therefore think of roughness as an increase in dimension: a rough curve has a dimension between 1 and 2, and a rough surface has a dimension somewhere between 2 and 3 . The dimension of a fractal curve is a number that characterizes the way in which the measured length between given points increases as the scale decreases.

Brownian motion is a classical example of a process that has a fractal dimension of 2 (Mandelbrot 1967). It occurs in microscopic particles and is the result of random movement by molecules (air, water, fluid, etc.). The path of such a particle is a "random walk" in which both direction and distance are uniformly distributed random variables. So, in moving from a starting location in space to a certain final location, the movement path taken by the particle is almost certain to fill the whole space before it reaches the exact point that is taken as a destination.

Summarizing, the fractal dimension indicates the degree of detail or crinkliness in the object. For a large number of geological objects it is a valuable measure, especially in understanding the processes responsible for such objects (rock structures, crustal complexes, ore bodies, fractures, composition of minerals and rocks, etc.) and for predictive purposes.

Finally, it should be emphasized that here we use the word "fractal" in its widest possible sense, as a synonym to the word "scale-invariant". The strict definition covers only (statistically) self-similar structures. However, the lack of internal characteristic scales ("scale-invariance") can take a wide variety of forms: self-similarity (a coastline), self-affinity (Earth's surface), multifractality (patterns arising from turbulent mixing), power-law distributions (leucosomes in migmatites, see below), etc.

\section{FRACTALITY IN GEOLOGY}

A power-law distribution (fractal in the loose sense) is the simplest statistical distribution that is scale-invariant, while other common distributions, such as the normal (Gaussian) and log-normal, have a characteristic length-scale or time in their definition. At present we know many examples of such scale-invariant, power-law distributions in nature, including geology and geophysics. For example, topography on the Earth, Moon, and Venus is well approximated by a Brownian motion (fractal number $D=2$ ). Hurst et al. (1965) showed that time series of river discharges, lake levels, but also thickness of tree rings and varves give Hurst exponents of around $H \approx 0.75$ and fractal dimensions of $D \approx 0.5$. The Hurst exponent $(H)$ is the measure of the smoothness of fractal time series and can 
be related to fractal dimension by $H=E+1-D$, where $E$ is the Euclidean dimension ( $E=0$ for a point, 1 for a line, 2 for a surface, etc.). If $H=0.5$, the behaviour of the time-series is similar to a random walk.

One of the fundamental problems in geology is the statistical distribution of chemical elements in the Earth's crust and mantle. Extreme concentrations of elements lead to ore deposits within the crust. Cargill et al. (1981) and Turcotte (2002) showed that ore deposits satisfy fractal statistics. Cheng et al. (1994) used fractal techniques to separate geochemical anomalies from background noise and Zheru et al. (2001) quantified the fractal features of element distributions on mineral surfaces.

A number of authors have shown that mineral textures and distributions are fractal (e.g. Fowler 1995). Armienti \& Tarquini (2002) studied olivine crystal size distributions in xenoliths using fractal methods. Fractal analysis is also used in studies of magma mixing and mingling in different geological environments volcanic eruptions in Italy (De Rosa et al. 2002), in a plutonic complex in Greece (Diego \& Giampiero 2000), and in lava flows in Greece and Italy (Perugini et al. 2002; Poli \& Perugini 2002), or in mantle convection (Ten et al. 1997). A hierarchical fractal model of magma transport beneath Hawaii is proposed by Saw \& Chouet (1991).

It has long been observed that earthquakes have so-called Gutenberg-Richter scaling (magnitude-frequency), that is, the distribution of events according to size follows a simple power-law. In other words, if the number of events of a given size or larger is plotted versus that size, the result will be a straight line on a log-log plot. In observational data, the exponent-value (the slope of the line) varies from region to region.

Although some fracture systems are best described by scale-limited laws (lognormal, exponential), it is now recognized that power-laws and fractal geometry provide widely applicable descriptive tools for fracture system characterization (Bonnet et al. 2001). Vein thickness and the mechanism of vein growth can also be successfully studied by employing fractal analysis (Brooks et al. 1995) as well as percolation properties of veins and ore mineralization (Roberts et al. 1999).

Power-law distribution is also characteristic of turbidite sections (Rothman et al. 1994) and fractal analysis may help to qualify the dynamics of turbidite sedimentation. The pore structure in sedimentary rocks is also fractal (Dutta 2003) and porosity variations in sedimentary basins are self-affine fractals to a good approximation both horizontally and vertically (Pelletier \& Turcotte 1996). Malamud \& Turcotte (1999) used power-law (fractal) correlation to estimate the number of plumes and hotspots that are not accounted for in present geological observations. Finally, the observed fractal shape of sutured quartz grain boundary has its implications for geothermometry (Kruhl \& Nega 1996).

These examples cover many fields in geology and associated geosciences. However, the main message of a large number of these papers is that we are able to recognize the fractal properties of geological observations, but not always explain the phenomenon. This stage may point towards the emergence of a new paradigm. 


\section{MELT ACCUMULATION AND MIGRATION: AN EXAMPLE OF A FRACTAL APPROACH}

Melt is generated by partial melting on the micro- to millimetre-scale in its source region and may accumulate and ascend to form several kilometre-scale volumes in the form of intrusions, batholiths, and volcanic formations. The whole range of magmatic processes may involve over 15-20 orders of magnitude in scale and deals with a variety of physical-chemical processes on different scales and different levels within the crust and mantle. Timescales also vary over many orders of magnitude, from seconds to hours for hydrofracture propagation involved in ascent of dykes (Lister \& Kerr 1991; Clemens \& Mawer 1992; Bons et al. 2001) to many millions of years for a thermal event that causes partial melting and crustal restructuring (Brown et al. 1995; Petford et al. 2000).

One of the manifestations of partial melting, melt segregation and accumulation are migmatites - composite rocks, which display both metamorphic and magmatic components. Several hypotheses have been put forward for the formation of migmatites, such as partial melting (Winkler 1961), injection of foreign magmas (Sederholm 1907), metamorphic differentiation (Ashworth \& McLellan 1985), and metasomatism (Olsen 1984). The combination of partial melting and metasomatism is also believed to cause migmatite formation (Olsen 1984). In recent years, partial melting has been considered to be the only dominant migmatiteforming process.

Migmatites are abundant in the Estonian crystalline basement, which is covered by Phanerozoic sediments and only found in drill core (Puura et al. 1997). We examined the leucosome and magmatic vein statistics in two drill cores. Magmatic veins and leucosomes are not homogeneous within the Estonian basement. They vary from large (up to over $1 \mathrm{~m}$ wide) granitic sills and lenses to millimetre-scale thin lenses, veins, and patches. The latter are probably the result of local melting and limited melt segregation, while larger veins may be manifestations of larger-scale melt transport, segregation, and accumulation. Melt may have entered the system and/or may have left the system.

Drill core F-156 penetrates volcanic-sedimentary biotite gneisses of amphibolite facies origin in Eastern Estonia. About 450 leucosomes (see Fig. 2) and granitic veins were measured in a section of $40 \mathrm{~m}$. Only veins wider than $3 \mathrm{~mm}$ were recorded. The percentage of igneous material (leucosomes and granitic veins) is $24(9.7 \mathrm{~m}$ from $40 \mathrm{~m})$. The average leucosome and granitic vein size is 9.7 and $28 \mathrm{~mm}$, respectively. The results are presented in a log-log plot (Fig. 3).

Drill core F-265 consists of biotite-plagioclase and pyroxene amphibolites of amphibolite facies, likely of igneous origin. This drill core represents a different situation where a large number of granitic veins dominate in the mafic gneiss and proper leucosomes are small (less than $2 \mathrm{~mm}$ ) or absent and thus cannot be precisely measured. About 545 granitic veins were measured in a section of $94 \mathrm{~m}$ (Fig. 3). These veins form $26 \%$ of the whole rock section. This percentage is close to that of drill core F-156. 
The width of leucosomes was measured in a number of drill cores consisting of rock types formed in different pressure-temperature conditions (amphibolite to granulite facies metamorphism). The results were statistically analysed in order to find the best statistical description. In Fig. 2 the spectrum of leucosome thicknesses along drill core F-156 is shown as an example. Is this leucosome distribution random in space and is the leucosome size (width) random? These are important questions related to segregation and accumulation of melts (or fluids) within the crust and elsewhere. We found that the number of small leucosomes and veins was correlated to the number of large leucosomes and veins by a simple powerlaw:

$$
N_{>S}=k S^{-m},
$$

where $N_{>S}$ is the number of leucosomes larger than size $S, k$ is the number of leucosomes larger than unit size, and $m$ is the distribution exponent (Fig. 3). Both drill cores show a power-law distribution from about 5 to $1000 \mathrm{~mm}$, about two orders of magnitude. In both cases the exponent $m \approx 1.15$. Drill core F-265 has only granitic veins wider than a few millimetres. Two types of veins could, however, be distinguished in drill core F-156: yellow to pink granitic-pegmatitic veins and pale white veins. When these two populations are plotted separately (Fig. 3A, B), we obtain the exponents $m \approx 1.1$ and $m \approx 1.9$, respectively. Such distributions are abundant in nature, as mentioned above. We found similar distributions in leucosome measurements at outcrops (for example in the Masku area, Finland, and in the Labrador Peninsula, Canada). Relying upon that, we may provisionally conclude that leucosome sizes, as well as leucosome spacing in the rock section, are not random values, but obey certain more complex rules. The box-counting method has been used to study leucosome distribution along these rock sections (Fig. 4). The results suggest that leucosome and granitic vein distribution in drill cores

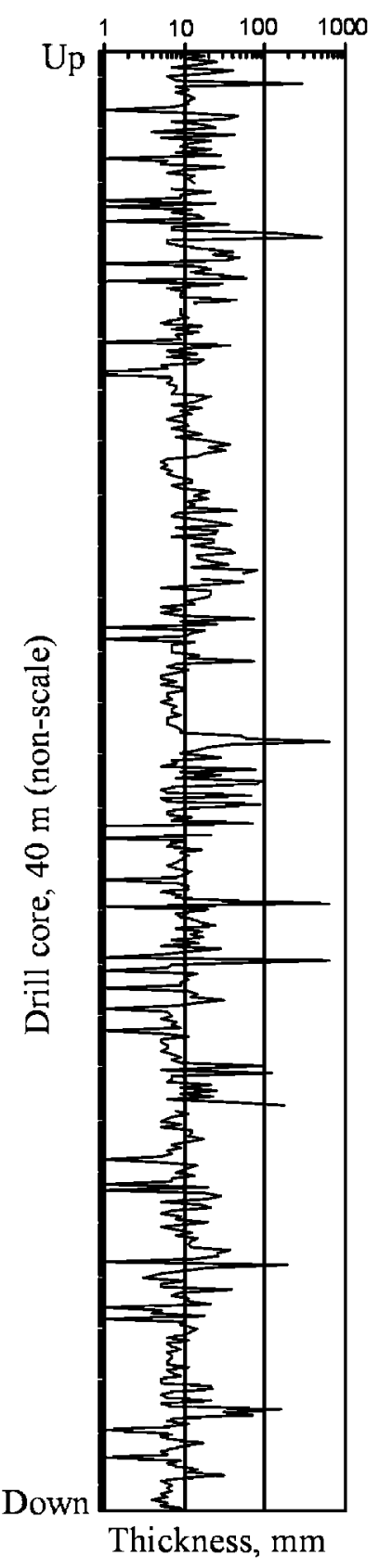

Fig. 2. Thicknesses of leucosomes in drill core F-156. The values are plotted in order of occurrence along the drill core from top to bottom. 

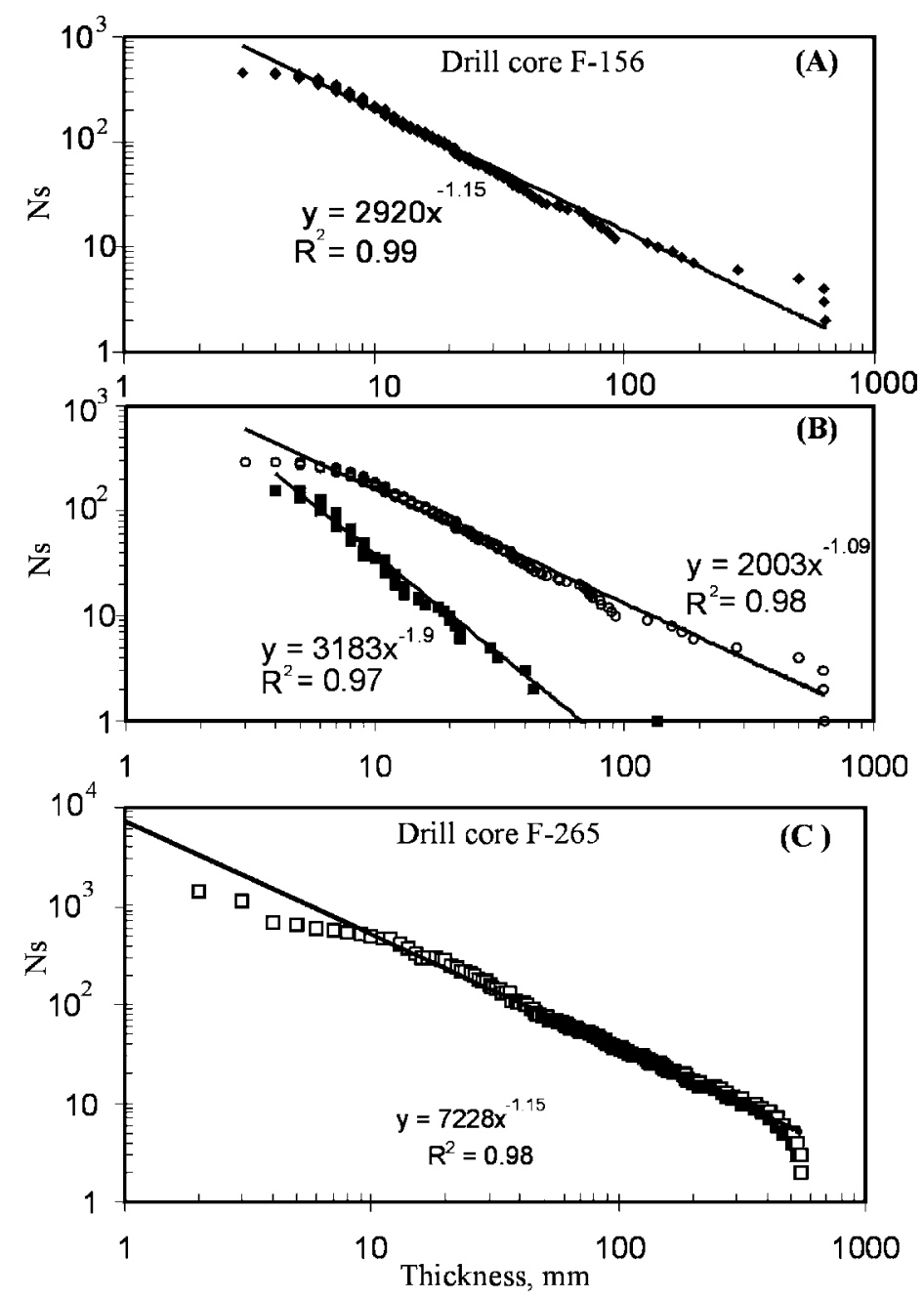

Fig. 3. (A) Thickness distribution of veins and leucosomes along a one-dimensional section of drill core F-156. (B) Both in situ leucosomes (filled squares) and granitic veins (open circles) show a power-law thickness distribution. (C) Thickness distribution of leucosomes along a one-dimensional section of drill core F-265.

F-156 and F-265 is not random but obeys certain rules, which are exemplified by good trends on similar log-log plots. In both cases the slopes (exponent) are similar: 0.77 for drill core F-256 and 0.79 for F-156 when studying the range between 13 and $650 \mathrm{~mm}$. Squeezing the range to 20-600 $\mathrm{mm}$ lowers the exponent slightly ( 0.74 and 0.76 , respectively).

Despite the differences in the size of measured leucosomes and veins, differences in host rock types and formation conditions, there are similarities between the cumulative thickness distributions in drill cores F-156 and F-265 

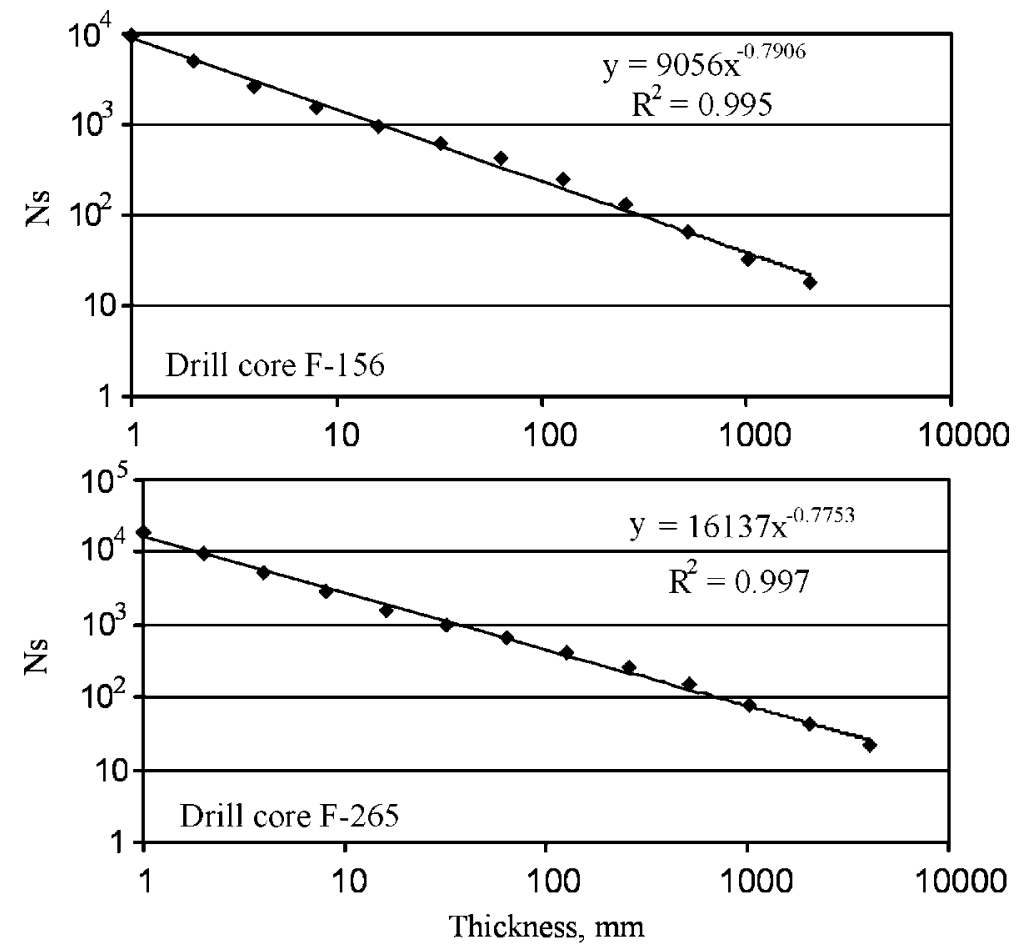

Fig. 4. Spatial distribution of leucosomes and granitic veins obtained by the box-counting method in drill cores F-156 and F-265.

(Fig. 3). Both give an exponent of $m \approx 1.15$. Both, especially F-156, show a bend-off at the largest and smallest widths of the range. A flattening off at the small end of the range is a common censoring effect: not all of the smallest veins are counted, because they are difficult to recognize. Small (2-3 $\mathrm{mm}$ and less) veins are therefore underrepresented in the count. The bend-off at the large end of the spectrum is less straightforward. This may be caused by the poor statistics at that end of the range: there are very few metre-size veins, and they may lie outside the section analysed. Another possibility is that there is a certain lengthscale $(\sim 1 \mathrm{~m})$, where the distribution actually breaks down, or changes. It could, for example, be that large veins have a higher chance to leave the system, and ascend through the crust.

The key aspect of the power-law distributions is the absence of a characteristic length-scale in leucosome thickness, and as a consequence, in the magma formation process(es). All power-law and fractal distributions in nature must, however, have upper and lower bounds. This topic has usually not always been emphasized in previous studies. In the case of migmatization and granite melt formation the lower bound is about the micrometre-scale. This lower bound has, 
however, no importance here, since micrometre-scale melt pockets or lenses could not be adequately measured anyway. In practice, $2 \mathrm{~mm}$ is the minimum size of the leucosome which can be measured. The upper bound is unknown. In our measurements we find power-law distributions up to about the metre-scale, i.e. over up to 2-3 orders of magnitude. As mentioned above, there may be a change in behaviour at about the metre-scale, but this is also the end of the range of our measurements.

The presented data set of leucosomes and veins as well as other measurements in Finland and Canada (not presented here) shows good power-law distributions with exponents usually between 1.0 and 1.9 (see Fig. 3). We should, however, stress that the thickness-distribution exponent along a linear section cannot be simply equated with the actual volume-distribution exponent (fractal dimension) of veins in a partial melt.

Migmatites record a "frozen" situation of granitic melt formation, from the time of solidification of the system. There is little direct evidence on how much of melt has left the system under observation (outcrop) or how much melt has been imported from outside. Chemical analyses indicate that at least many granulite facies rocks experienced melt loss (Guernina \& Sawyer 2003), but physical traces of this melt or its pathways are very rare. Similarly, we encounter difficulties when we need to calculate the depletion percentage of the country rock that produced the melt.

There have been attempts to model melt and fluid accumulation and migration numerically and using the analogue modelling approach (e.g. Bons \& van Milligen 2001; Bons et al. in press). These results also indicate that the melt system may quickly develop into a self-organized critical state (Bak et al. 1987). In this state, the distribution of melt volumes in the host rock can be described by a powerlaw, similar to leucosome thickness-distribution in the studied rocks. The exponent value for melt batches with different size in the source commonly lies between $2 / 3$ and 1 and is irrespective of details such as shape of single batches (Bons \& Arnold 2003). It is also important to note that modelling results suggest that in the self-organized critical state, the system is capable of discharging any additional melt without any further change to system itself, which also shows that full connectivity of melt batches (melt network) needs not to be reached in the system. The latter was usually assumed as a prerequisite for successful melt segregation and accumulation (Weinberg 1999). Deformation may enhance melt extraction efficiency, as it increases the mobility of melt-filled hydrofractures and increases accumulation. The modelling results show that it is possible to efficiently drain melt from a source, when the melt volume distribution exponent is close to $2 / 3$, where the maximum accumulation is achieved and as much as $50 \%$ of all mass resides in the single largest batch in the system. In this case very little evidence would remain in the form of leucosomes in the host rock.

In case of the data from Estonian basement rocks, we are dealing with

(a) a power-law distribution of leucosome thickness (total set of data: $m$ (exponent) $=1.15$; Fig. 3 ) and 
(b) a fractal distribution of leucosomes along a rock section $(D=0.77-0.79$; Fig. 4).

Let us study in more detail the implications of the power-law relationship between the sizes and numbers of leucosomes and melt batches:

$$
N_{>S}=k S^{-m}
$$

where $k=S_{\max }^{m}$, and $S_{\max }$ is the expected largest batch size. First we note that the above law is statistical, and hence, the real largest batch size can be somewhat (e.g. 30\%) smaller or larger than $S_{\max }$; the value of $k$ is to be found by least-square fitting of the real data to this scaling law.

The basic characteristic here is the scaling exponent $m$; small values of the exponent $m$ imply relatively few small batches. It is easy to see that for $m \geq 1$, the mass of the melt is dominated by small batches. Indeed, the total volume of batches is expressed via the distribution function: $A_{\text {tot }}=\int S f_{S} \mathrm{~d} S$ with

$$
f_{V}=-\frac{\partial N S}{\partial S}=\frac{m S_{\max }^{m}}{S^{m+1}}
$$

Notice that the integrand $S f_{S} \propto S^{-m}$, and that therefore the integral (the total volume of batches) is dominated by small batches if $m>1$. In the opposite case $(m<1)$, a straightforward calculation leads us to $V_{\text {tot }}=\int S f_{S} \mathrm{~d} S=m S_{\text {max }} /(1-m)$. Hence, the ratio of the volume of the largest batch to the total volume is given by:

$$
S_{\max } / V_{\text {tot }}=(1-m) / m \text {. }
$$

At $m=2 / 3,50 \%$ or more of all melt is in the single largest melt batch, while this percentage goes down to $0 \%$ at $m=1$ (when all the melt resides in small batches). Therefore we expect that the real values lie between $m=2 / 3$ and $m=1$ (which forms the boundary between accumulation and dispersion), as predicted theoretically (Bons \& Arnold 2003). This conclusion is independent of the shape of the melt batches and is not only valid for spheres, but also for lenticular hydrofractures or any other shape.

Finally, it should be emphasized that the exponent $m$ in the above formulae is not equal to the scaling exponent $\gamma$ of the magmatic vein width, $N_{>d} \approx k d^{-\gamma}$. In order to show this (and derive the expression for $\gamma$ ), suppose a random point in the net volume is coined. Let us estimate the probability of getting inside a batch, the diameter of which exceeds $d$ :

$$
p \approx d^{3} N_{>d^{3}} \propto d^{3-3 m}
$$

Similar calculations can be done for the width distribution function, 


$$
p \approx d N_{>d} \propto d^{1-\gamma} .
$$

Comparing these two estimates leads us to the conclusion that $3-3 m=1-\gamma$, and therefore $\gamma=3 m-2$. Thus, the expected range of exponents $2 / 3 \leq m \leq 1$ translates into $0 \leq \gamma \leq 1$ ( 0 corresponding to half of the total melt residing in the largest batch, and 1 to almost all the melt residing in the smallest batches). The fact that exponents $\gamma$ close to unity, observed in the drill cores, suggests that the melt volume distribution in the migmatites has an exponent $m \approx 1$, suggesting poor accumulation.

Knowing the power-law of the size-number distribution for the melt batches, we can estimate the total volume of the melt phase, as well as the relative contributions of the largest batch (dominant for $m<1$ ) and of the smallest batches (dominant for $m>1$ ). Based upon these relationships of melt batch distribution, we are able to quantify the total melt volume produced. Taking an arbitrary crustal section of $100 \times 100 \mathrm{~km}$ with a thickness of $10 \mathrm{~km}$, which can be regarded as a magmatic system during regional metamorphism, we are able to calculate melt volume in any part of the system under consideration. A total melting of a $1 \mathrm{~km}^{3}$ per $1 \mathrm{~km}^{2}$ crustal column seems a reasonable value for total melt volume (Zen 1992), which gives $V_{\text {tot }}=10^{4} \mathrm{~km}^{3}$. Now, considering the above relationships we can calculate that $1 \mathrm{~m}^{3}$ may contain up to 900 leucosomes with volumes between $1 \mathrm{~cm}^{3}$ and $1 \mathrm{dm}^{3}$ at $m=0.97$. Close to an end member case $(m=2 / 3)$, the number of melt veins with this volume is nil, since most of melt is accumulated into larger veins. This also applies to extracted melt volumes (dykes, formation of granitic intrusions, etc.). If in the above example the extraction threshold volume is set at $1 \mathrm{~km}^{3}$, about $94 \%$ of melt is extracted if $m=0.67$ and the extraction efficiency reduces to zero at $m=1$.

\section{CONCLUSIONS}

The main conclusions can be summarized as follows:

1. A large number of geological objects show a power-law or fractal distribution, which suggests that these objects do not require any characteristic length-scale or time in their definition. Fractals can be effectively used in studies of magma mixing and mingling, mantle convection, lava flows, percolation properties of veins, ore mineralization, etc.

2. The width of migmatitic leucosomes in the Estonian basement rocks also follows power-law distribution and shows fractal properties. Despite the differences in size and number of measured leucosomes and veins, differences in host rock types and formation conditions, the studied leucosome thickness shows good power-law distributions with exponents usually between 1.0 and 1.9. The same exponents have been obtained from studies of leucosomes in different outcrops (e.g. southern Finland). The spacing of leucosomes in rock section is not a random feature, but shows fractal distribution $(D=0.77-0.79)$. 
3. On the basis of the power-law of the size-number distribution for the melt batches we estimated the total volume of the melt phase, as well as the relative contributions of the largest batch (dominant for $m<1$ ) and of the smallest batches (dominant for $m>1$ ). The relationship between the magmatic leucosome width-distribution exponent, and the melt batch size-distribution was derived.

\section{ACKNOWLEDGEMENTS}

AS and JK acknowledge financial support from the Estonian Science Foundation (grants Nos. 5301 and 4615, and 5036, respectively). Jochen Arnold and Juho Kirs are thanked for valuable comments on the manuscript.

\section{REFERENCES}

Armienti, P. \& Tarquini, S. 2002. Power law olivine crystal size distributions in lithospheric mantle xenoliths. Lithos, 65, 273-285.

Ashworth, J. \& McLellan, E. 1985. Textures. In Migmatites (Ashworth, J., ed.), pp. 180-203. Blackie, Glasgow.

Bak, P., Tang, C. \& Wiesenfeld, K. 1987. Self-organized criticality: an explanation of 1/f noise. Phys. Rev. Lett., 59, 381-384.

Bonnet, E., Bour, O., Odling, N. E., Davy, P., Main, I., Cowie, P. \& Berkowitz, B. 2001. Scaling of fracture systems in geological media. Rev. Geophys., 39, 347-383.

Bons, P. D. \& Arnold, J. 2003. Accumulation and self-organization in hydrofracture transport of fluids. J. Geochem. Exp., 78-79, 667-670.

Bons, P. D. \& van Milligen, B. P. 2001. A new experiment to model self-organized critical transport and accumulation of melt and hydrocarbons from their source rocks. Geology, 29, 919-922.

Bons, P. D., Dougherty-Page, J. \& Elburg, M. A. 2001. Stepwise accumulation and ascent of magmas. J. Metamorphic Geol., 19, 627-633.

Bons, P., Arnold, J., Elburg, M., Kalda, J. \& Soesoo, A. Melt accumulation from partially molten rocks. Lithos (in press)

Brooks, C., Brantley, S. \& Fisher, D. 1995. Power-law vein-thickness distribution and positive feedback in vein growth. Geology, 23, 975-978.

Brown, M., Averkin, Y. A., McLellan, E. L. \& Sawyer, E. W. 1995. Melt segregation in migmatites. J. Geophys. Res., 100, 15655-15679.

Cargill, S. M., Root, D. H. \& Bailey, E. H. 1981. Estimating usable resources from historical industrial data. Econ. Geol., 76, 1081-1095.

Cheng, Q., Agterberg, F. P. \& Ballantyne, S. P. 1994. The separation of geochemical anomalies from background by fractal methods. J. Geochem. Exp., 51, 109-130.

Clemens, J. D. \& Mawer, C. K. 1992. Granitic magma transport by fracture propagation. Tectonophysics, 204, 339-360.

De Rosa, R., Donato, P. \& Ventura, G. 2002. Fractal analysis of mingled/mixed magmas: an example from the Upper Pollara eruption (Salina Island, southern Tyrrhenian Sea, Italy). Lithos, 65, 299-311.

Diego, P. \& Giampiero, P. 2000. Chaotic dynamics and fractals in magmatic interaction processes: a different approach to the interpretation of mafic microgranular enclaves. Earth Planet. Sci. Lett., 175, 93-103.

Dutta, T. 2003. Fractal pore structure of sedimentary rocks: simulation by ballistic deposition. J. Geophys. Res., 108, 101029-101035. 
Feder, J. 1988. Fractals. Plenum Press, New York and London.

Fowler, A. D. 1995. Mineral crystallinity in igneous rocks-fractal methods. In Fractals in the Earth Sciences (Barton, C. \& La Pointe, P., eds.), pp. 237-249. Plenum, New York.

Guernina, S. \& Sawyer, E. W. 2003. Large-scale melt-depletion in granulite terranes: an example from the Archean Ashuanipi Subprovince of Quebeq. J. Metamorphic Geol., 21, 181-201.

Hurst, H. E., Black, R. P. \& Simaika, Y. M. 1965. Long-Term Storage: an Experimental Study. Constable, London.

Kruhl, J. \& Nega, M. 1996. The fractal shape of sutured quartz grain boundaries: application as a geothermometer. Geol. Rundsch., 85, 38-43.

Lister, J. R. \& Kerr, R. C. 1991. Fluid-mechanical models of crack-propagation and their application to magma transport in dykes. J. Geophys. Res., 96, 10049-10077.

Malamud, B. D. \& Turcotte, D. L. 1999. Self-affine time series: I. Generation and analyses. Adv. Geophys., 40, 1-90.

Mandelbrot, B. 1967. How long is the coast of Britain? Statistical self-similarity and fractional dimension. Science, 156, 636-638.

Mandelbrot, B. 1982. The Fractal Geometry of Nature. W. H. Freeman Press, New York.

Mandelbrot, B. \& Van Ness, J. 1968. Fractional Brownian motions, fractional noises and applications. SIAM Rev., 10, 422-437.

Olsen, S. N. 1984. Mass-balance and mass-transfer in migmatites from the Front Range, Colorado. Contrib. Mineral. Petrol., 85, 30-44.

Peitgen, H.-O., Jurgens, H. \& Saupe, D. 1992. Fractals for the Classroom. Springer-Verlag.

Pelletier, J. D. \& Turcotte, D. L. 1996. Scale-invariant topography and porosity variations in sedimentary basins. J. Geophys. Res., 101, 28165-28175.

Perugini, D., Poli, G. \& Gatta, G. 2002. Analysis and simulation of magma mixing processes in 3D. Lithos, 65, 313-330.

Petford, N., Cruden, A. R., McCaffrey, K. J. W. \& Vigneresse, J.-L. 2000. Granite formation, transport and emplacement in the Earth's crust. Nature, 408, 669-673.

Poli, G. \& Perugini, D. 2002. Strange attractors in magmas: evidence from lava flows. Lithos, 65 , 287-297.

Puura, V., Klein, V., Koppelmaa, H. \& Niin, M. 1997. Precambrian basement. In Geology and Mineral Resources of Estonia (Raukas, A. \& Teedumäe, A., eds.), pp. 27-34. Estonian Academy Publishers, Tallinn.

Roberts, S., Sanderson, D. \& Gumiel, P. 1999. Fractal analysis and percolation properties of veins. In Fractures, Fluid Flow and Mineralisation (McCaffrey, K., Lonegran, L. \& Wilkinson, J., eds.). Geol. Soc. London Spec. Publ., 155, 7-16.

Rothman, D., Grotzinger, J. \& Flemings, P. 1994. Scaling in turbitite deposition. J. Sedim. Res., 64, 59-67.

Saw, H. \& Chouet, B. 1991. Fractal hierarchies of magma transport in Hawaii and critical selforganisation of tremor. J. Geophys. Res., 96, 10191-10207.

Sederholm, J. 1907. On granite and gneiss. Bull. Comm. Geol. Finl., 23, 1-110.

Ten, A., Yuen, D., Podladchikov, Y., Larsen, T., Pachepsky, E. \& Malevsky, A. 1997. Fractal features in mixing of non-Newtonian and Newtonian mantle convection. Earth Planet. Sci. Lett., 146, 401-414.

Turcotte, D. 2002. Fractals in petrology. Lithos, 65, 261-271.

Weinberg, R. F. 1999. Mesoscale pervasive felsic magma migration: alternatives to dyking. Lithos, 46, 393-410.

Winkler, H. 1961. Die Genese von Graniten und Migmatiten auf Grund neuer Experimente. Geol. Rundsch., 61, 347-364.

Zen, E. 1992. Using granite to image the thermal state of the source terrain. Trans. Royal Soc. Edinburgh Earth Sci., 83, 107-114.

Zheru, Z., Huahei, M. \& Cheng, Z. 2001. Fractal geometry of element distribution on mineral surfaces. Math. Geol., 33, 217-228. 


\title{
Fraktalid geoloogias: fraktalite kasutusvõimalusi osalise ülessulamise protsesside uurimisel
}

\author{
Alvar Soesoo, Jaan Kalda, Paul Bons, Kristjan Urtson ja Volli Kalm \\ Viimasel aastakümnel on hoogustunud fraktaalmeetodite kasutamine geoloo- \\ gilistes teadustes, eeskätt selliste geoloogiliste objektide puhul, mida on võimalik \\ kirjeldada pikkuse, laiuse või aja mõõtmisega. Fraktaalset lähenemist on kasuta- \\ tud magma segunemisprotsesside, vahevöö konvektsiooni, mineraalsete soonte \\ kasvu ja mineralisatsiooni ning teiste protsesside uurimisel. Artiklis on näidatud, \\ et Eesti aluskorrakivimites paiknevate migmatiitsete leukosoomide paksused \\ on kirjeldatavad fraktaaljaotuse abil. Erinevates kivimitüüpides mõõdetud leuko- \\ soomide ja graniitsete soonte paksused $v s$ mõõdetud objektide arv logaritmilisel \\ graafikul (astmefunktsioon) jääb eksponendivahemikku 1,0 ja 1,9. Mõõdetud \\ ühedimensionaalse leukosoomi laiuse jaotuse eksponendi ja magmakeha suuruse \\ vaheline matemaatiline seos on tuletatud.
}

